\title{
Emoções experienciadas no processo de construção de narrativas digitais no Scratch
}

\author{
Eliana Alice Brochado ${ }^{\mathrm{I}, \mathrm{II}}$ \\ Gabriel Gerber Hornink ${ }^{\mathrm{III}, \mathrm{IV}}$
}

http://dx.doi.org/10.24109/2176-6681.rbep.101i259.3813

\section{Resumo}

O uso de tecnologias digitais educacionais tem se tornado objeto de pesquisa na atualidade. No entanto, a compreensão das emoções experienciadas durante a utilização de tais tecnologias no ambiente escolar carece de maior pormenorização. Dessa forma, desenvolveu-se uma pesquisa de natureza aplicada, com abordagem mista, arquitetando um

Universidade Federal de Alfenas (Unifal). Alfenas, Minas Gerais, Brasil. E-mail: <elianabrochado@gmail. com>; <https://orcid. org/0000-0003-2845-8809>.

II Mestre em Educação pela Universidade Federal de Alfenas (Unifal). Alfenas, Minas Gerais, Brasil.

III Universidade Federal de Alfenas (Unifal). Alfenas, Minas Gerais, Brasil. E-mail: <gabriel.hornink@unifal-mg edu.br $>$; $<$ https://orcid. org/0000-0003-0388-4027>.

Iv Doutor em Ciências pela Universidade Estadual de Campinas (Unicamp). Campinas, São Paulo, Brasil. estudo de caso exploratório e descritivo com o objetivo de compreender como os alunos, ao construírem narrativas digitais por meio de programação lúdica em um software chamado Scratch, apropriavam-se do gênero. Para tal, utilizou-se a técnica de observação participante, criando-se um teste (dos estados emocionais) que emprega métodos estatísticos para a construção e apresentação dos dados produzidos com alunos dos $6^{\circ}$ e $7^{\circ}$ anos do ensino fundamental em aulas de Língua Portuguesa. Os princípios das teorias socioculturais de aprendizagem e das emoções embasaram teoricamente as reflexões deste artigo. Os resultados indicam a predominância de emoções positivas durante o processo e o fato de que a presença delas favoreceu a motivação para a construção dos projetos.

Palavras-chave: cultura digital; emoções; estudos socioculturais; tecnologia educacional. 


\section{Abstract \\ Emotions experienced in the process of digital narrative construction in Scratch}

The use of educational digital technologies has lately become an object of research, since understanding emotions experienced during the use of such technologies in the school environment needs further detailing. Thus, a research of applied nature was developed, using a mixed approach, and designing an exploratory and descriptive case study in order to understand how students, when constructing digital narratives through playful programming in a software called Scratch, appropriated the genre. To this end, we used the participant observation technique, created a test (Emotional Status Test) and used statistical methods for the gathering and presentation of data produced with students from the 6th and 7th grades in Portuguese language classes. The principles of sociocultural learning and emotions theories underpinned our reflections. The results indicate the predominance of positive emotions during the process and that the presence of such emotions may have favored students' motivation for the construction of projects.

Keywords: digital culture; educational technology; emotions; sociocultural studies.

\section{Resumen \\ Emociones experimentadas en el processo de construcción de narrativas digitales en Scratch}

El uso de tecnologías digitales educativas se ha convertido hoy en el objeto de investigación. Sin embargo, comprender las emociones experimentadas durante el uso de tales tecnologías en el entorno escolar necesita más detalles. Por lo tanto, desarrollamos una investigación de naturaleza aplicada, con un enfoque mixto, diseñando un estudio de caso exploratorio y descriptivo para comprender cómo los estudiantes, al construir narrativas digitales a través de la programación lúdica en un software llamado Scratch, se apropiaron del género. Con este fin, utilizamos la técnica de observación participante, creamos una prueba (Prueba de estado emocional) y utilizamos métodos estadísticos para la construcción y presentación de datos producidos con estudiantes de $6^{\circ}$ y $7^{\circ}$ grado en clases de lengua portuguesa. Los principios de las teorias del aprendizaje sociocultural y emociones teóricamente sustentaron nuestras reflexiones. Los resultados indican el predominio de emociones positivas durante el proceso y que la presencia de tales emociones puede haber favorecido la motivación para la construcción de proyectos.

Palabras clave: cultura digital; emociones; estudios socioculturales; tecnología educativa. 


\section{Introdução}

As tecnologias digitais de informação e comunicação (TDIC) estão presentes em diversos setores da sociedade - dentre eles, o ambiente escolar e têm despertado a atenção de pesquisadores em busca da compreensão de seu uso e, consequentemente, das potencialidades e desafios desse uso para o ensino e a aprendizagem. Citam-se como exemplo Rodrigues e Teles (2019), que estudaram o emprego de mensagens eletrônicas instantâneas como recurso didático e constataram que, se houver planejamento docente, esse pode ser um recurso exitoso. Nessa direção, busca-se entender como os alunos se apropriam (Wertsch, 1993, 1999) de narrativas digitais (ND), determinando, além disso, alguns objetivos específicos, com a intenção de: a) identificar como o aluno se sentia (emoções e manifestações expressivas, linguísticas e gestuais) ao usar um software denominado Scratch; e b) observar o impacto das emoções experimentadas durante o processo de construção de ND.

O intuito foi compreender, como sugere Hornink (2010), os aspectos sociais, cognitivos e afetivos que envolvem o uso de artefatos tecnológicos, considerando-os instrumentos culturais de mediação. Desse modo, primeiramente, este artigo apresenta teoricamente como se dá o processo de apropriação segundo Wertsch (1993, 1999). Na sequência, demonstra-se a concepção de emoção aqui adotada e, em seguida, delineiam-se os materiais e métodos utilizados para chegar aos resultados apresentados nas considerações finais.

\section{Teoria da Ação Mediada}

Para o autor, ferramentas técnicas são aquelas com materialidade aparente, como um lápis, um computador ou uma bicicleta; as ferramentas psicológicas são as que têm aparente imaterialidade, como os signos, os sinais gráficos ou a fala. No entanto, ambas são consideradas por Wertsch (1993, 1999) ferramentas materiais.

2 1) Agente: indivíduo - ou grupo - que praticou um ato; 2) ato: o que se passou com o agente dentro de uma cena; 3) cena: local e tempo em que se sucederam as transformações vividas pelos agentes ao se valerem de agências; 4) agência: instrumentos - ferramentas técnicas ou psicológicas utilizados pelo agente sempre com certo propósito; 5) propósito: os motivos, isto é, os porquês de uma ação.

O psicólogo norte-americano James W. Wertsch, baseando-se fundamentalmente em Vigotsky, Bakhtin e Burke, estruturou a Teoria da Ação Mediada (TAM), cujo princípio é compreender um instrumento em uma unidade de análise, isto é, observar a interação de um agente no momento em que está agindo com uma ferramenta, seja ela técnica ou psicológica ${ }^{1}$. Para o autor, uma ação envolve cinco elementos ${ }^{2}$, como postulou Burke (1969 apud Wertsch, 1999), e é na junção deles que se entende plenamente a ação de um agente ao usar uma ferramenta. O psicólogo ainda esclarece que é possível, no momento de análise, dar atenção especial a um dos elementos, mas nunca os isolar.

Dessa forma, seguindo os princípios propostos por Wertsch (1988, 1993, 1999), analisa-se o processo de produção de ND dos sujeitos envolvidos na pesquisa e o quanto estavam dispostos a deixar marcas pessoais - de autoria - em tais textos, a interagir com o usuário, a deixar transparecer o meio no qual vive em sua produção. No entanto, Werstch $(1993,1999)$ define dois níveis para o processo de construção do conhecimento: domínio e apropriação. O autor esclarece que, ao se apropriar de algo, o agente toma para si, isto é, deseja, em um processo permeado de resistência, valer-se de uma ferramenta para agir, enquanto que, quando a ação acontece apenas 
em um nível externo, seria mais adequado dizer que o agente sabe fazer, realizar, executar a ação, por isso nomeia tal processo domínio.

Dessa forma, com base em Werstch (1999) e Hornink (2010), este artigo defende que o processo de apropriação é permeado por subjetividade, portanto, não só os aspectos sociais e cognitivos devem ser identificados e analisados, mas também os afetivos. Para tal, apresenta-se a seguir a concepção de emoção utilizada para demonstrar os resultados deste estudo.

\section{Concepção sociocultural de emoção}

Longhi et al. (2007) e Reis et al. (2015) discorrem sobre as dificuldades de definir termos relacionados à emoção devido ao número de correntes teóricas que abordam essa temática. Por exemplo, para Vigotsky (2004), em uma perspectiva histórico-cultural, afeto e emoção são vistos como sinônimos, enquanto para o neurocientista Damásio (1996) há sutis diferenças conceituais entre esses vocábulos.

Diante de tais condições, tendo em vista os princípios socioculturais de aprendizagem, este artigo se vale de uma concepção teórica na qual as emoções são compreendidas como "[...] atuações culturais aprendidas e realizadas nas ocasiões oportunas" (Rebollo-Catalán; Hornillo-Gómez; García-Pérez, 2006, p. 34, tradução nossa³). Ainda segundo Rebollo-Catalán e Hornillo-Gómez (2010), as emoções não são processos individuais e são mediadas pelas ferramentas, favorecendo a construção de certa identidade dentro dos contextos nos quais são vivenciadas. Essa concepção de emoção tem forte ligação com os princípios da Teoria da Ação Mediada, pois, para Wertsch (1999), a mente humana deve ser compreendida somente quando inserida em um contexto cultural, histórico e institucional, o que leva este estudo a unir as duas propostas para analisar os dados recolhidos.

Para auxiliar esse processo de identificação e apreensão das emoções vivenciadas pelos sujeitos, este artigo se apoia na afirmação de que há um elemento subjetivo do enunciado, o qual Bakhtin (1997) denomina intuito, que permite aos parceiros identificarem o "querer-dizer" do outro. O autor orienta que há nos enunciados muitas palavras que são dos outros; isto é, para formar enunciados próprios, os sujeitos se baseiam em vivências anteriores. Dessa maneira, indivíduos aprendem a expressar aquilo que está na subjetividade e no contexto em que se está inserido. Sendo assim, é só no contexto em que ocorre a ação que se entende se um choro, por exemplo, demonstra tristeza, decepção ou alegria.

Esta investigação se guiou por esses princípios para traçar a triangulação (Morse, 1991) dos dados produzidos durante a elaboração das ND.

\section{Materiais e métodos}

Este estudo se baseia no uso de uma linguagem de programação chamada Scratch, que permite com o simples clicar e arrastar de blocos
"[...] las emociones son actuaciones culturales aprendidas y realizadas en las ocasiones oportunas." 
lógicos, como mostra a Figura 1, a construção de ND. Essas narrativas foram construídas com alunos regularmente matriculados nos $6^{\circ}$ e $7^{\circ}$ anos do ensino fundamental, com a finalidade de compreender o processo de apropriação de tal gênero e os aspectos afetivos implicados. Com o intuito de se aproximar de uma realidade pedagógica, arquitetou-se uma pesquisa de natureza aplicada. A questão central era como o uso do Scratch pode levar à apropriação de ND. Segundo Yin (2001), perguntas como essa requerem uma investigação que permita conhecer profundamente o problema.

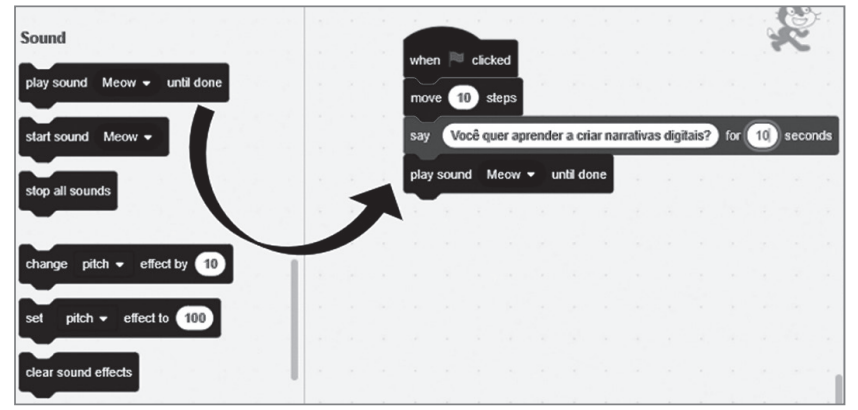

Figura 1 - Exemplo de como clicar e arrastar blocos no Scratch

Fonte: Tela de um projeto no Scratch capturada pelos autores.

Scratch oportuniza a construção, o compartilhamento e a remixagem de histórias. Segundo Rodrigues (2019), essas possibilidades permitem ao aluno se posicionar na sociedade como protagonista, pois ele pode apresentar em sua narrativa aquilo que lhe é particular, que está inserido em sua vida real. Além disso, essa linguagem de programação é agradável, visual (Yukselturk; Altiok, 2017), lúdica, dinâmica e gratuita. Segundo Farias, Bonifácio e Ferreira (2015), a ferramenta também é bastante usual, portanto, como ferramenta cultural de mediação, pode auxiliar como potencializadora "da cognição de maneira lúdica" (Brochado; Silva; Hornink, 2018, p. 10). Partindo desses pressupostos, Silva (2019, p. 145) constata que, se a construção de ND for mediada por indivíduos com saberes diferentes, de maneira colaborativa entre os pares, "o domínio computacional, a construção de narrativas autorais e a criatividade literária" serão favorecidos.

Dessa forma, seguindo as orientações do metodólogo Yin (2001), desenvolveu-se um caso-piloto (CP), em 2017, com dez alunos do $6^{\circ}$ ano de uma escola pública do Sul de Minas Gerais, num período de 24 horas, distribuídas em nove encontros, com o objetivo de conhecer melhor o projeto de pesquisa elaborado. Em seguida, após as reestruturações necessárias, desenvolveu-se, em 2018, na mesma escola, o estudo de caso (EC) propriamente dito, cujos dados são apresentados neste trabalho. Tal ação totalizou 30 horas, distribuídas em 12 encontros, com 16 alunos do $7^{\circ}$ ano, com o intuito de explorar e descrever em detalhes a ação proposta, considerando o contexto, conforme defende André (2005). 
Para permitir a ação dos sujeitos com a ferramenta e compreender o processo de apropriação de ND e as emoções envolvidas, foi realizada uma sequência didática (SD) aplicada em dois momentos ${ }^{4}$ : o primeiro, dentro do horário regular de aulas, com atividades que objetivavam a alimentação temática das produções; e o segundo, em virtude do espaço físico da sala de informática e do número de computadores em pleno funcionamento, no contraturno, com atividades relacionadas ao uso do Scratch. Nesse segundo momento da SD, a fim de cumprir os preceitos da TAM, a professora ${ }^{5}$ organizou os alunos em duplas heterogêneas, para propiciar a troca de saberes entre os agentes, haja vista a defesa que Wertsch $(1993,1999)$ faz de uma concepção distribuída (entre os pares) de aprendizagem.

A observação participante, de acordo com Meirinhos e Osório (2010), permite a inserção do pesquisador no contexto no qual as ações ocorrem. Com base nessa técnica, construiu-se um jornal de pesquisa, fonte extremamente relevante para um pesquisador em educação (Barbosa; Hess, 2010). Estruturou-se também, conforme Rebollo-Catalán et al. (2008, 2014), um teste - ao qual se deu o nome de Teste dos Estados Emocionais (TEE) com questões fechadas e uma aberta. Tal questionário foi estruturado com emoticons ${ }^{6}$ de acesso livre, em uma escala com variação entre 1 (discordo totalmente) e 5 (concordo totalmente) (Likert, 1932), contendo cinco emoções positivas (satisfeito/a, feliz, empolgado/a, comprometido/a e orgulhoso/a) e cinco emoções negativas (ansioso/a, envergonhado/a, enraivecido/a, decepcionado/a e entediado/a), além de uma questão aberta, a qual permitiu ao sujeito explicar suas vivências e emoções ou ainda mencionar alguma emoção não observada no teste.

Reconhecendo que as abordagens qualitativa e quantitativa se complementam (Minayo, 2002), ambas foram utilizadas para analisar os dados à luz do referencial teórico delineado.

Partiu-se do princípio de que é preciso examinar, de acordo com a análise microgenética de Wertsch (1988, 1993, 1999), os enunciados (Bakhtin, 1997) produzidos pelos sujeitos para que fosse possível compreender o processo de apropriação das ND e, ao mesmo tempo, identificar e entender as emoções implicadas. Dessa maneira, por meio desses enunciados, coletados durante a observação das ações e também manifestados pelos sujeitos no TEE, buscou-se compreender a relevância das emoções nesse processo. Para selecionar as anotações das observações feitas no jornal de pesquisa, a noção de episódios de Mortimer et al. (2007 apud Mortimer et al., 2014) foi de grande importância, pois auxiliou na escolha das observações que respondiam à interrogação proposta. Quanto aos enunciados presentes no TEE, foram baseados nas etapas sugeridas por Bardin (2016) para, depois de uma leitura flutuante, codificar e categorizar os dados levando em conta as categorias pré-determinadas de acordo com as emoções listadas no questionário.

A partir da concepção de que os sujeitos aprendem as emoções conforme as ocasiões que vivenciam, buscou-se conhecer o que eles pensavam a respeito de cada uma das emoções presentes no teste. Permitiu-se que citassem exemplos e denominassem essas emoções em
4 Esta pesquisa foi aprovada pelo Comitê de Ética da Universidade Federal de Alfenas (Unifal) de Minas Gerais e seguiu os protocolos exigidos pela legislação vigente.

5 Este trabalho esteve integrado aos de outros membros do grupo de pesquisa Inovações Tecnológicas no Ensino (Unifal-MG), coordenado pelo professor Dr. Gabriel Gerber Hornink. De maneira mais direta, a pesquisa aqui abordada manteve ligação com a de Moisa Aparecida da Silva, que, além de pesquisadora do grupo, foi professora de Língua Portuguesa dos sujeitos desta investigação. Tanto a pesquisa de Moisa quanto a aqui apresentada tiveram objetivos diferentes, mas os mesmos sujeitos. De maneira indireta, este trabalho manteve também relação com a pesquisa de Augusto Márcio da Silva, pois aqui foram utilizados vídeos criados por esse pesquisador - e por outros membros do laboratório para desenvolver as atividades propostas na realização do trabalho de campo que levou à produção dos dados aqui apresentados.

6 Imagens ilustrativas, usadas em comunicação virtual, que buscam manifestar uma expressão facial. 
situações contextualizadas, a fim de evitar distorções nos resultados. Sendo assim, após cada encontro, os alunos recebiam o teste, individualmente, para que o respondessem. Após a realização de todos os encontros, utilizou-se estatística descritiva (Doria Filho, [s. d.]) para compreensão inicial dos dados.

A estatística também auxiliou no entendimento dos dados relativos às produções em si, ou seja, das ND. Para avaliar se houve ou não desenvolvimento do pensamento computacional (PC), utilizou-se o software gratuito Dr. Scratch, o qual apresenta uma pontuação (entre zero e três), avaliando sete itens (lógica, paralelismo, interatividade com o usuário, representação de dados, controle de fluxo, sincronização e abstração), isto é, as habilidades do PC de cada projeto. Após essa avaliação, estruturou-se uma tabela com tais valores e, em virtude do $n$ e por serem dados ordenativos, foram seguidas as orientações de Torman, Coster e Riboldi (2012) para realização de um teste estatístico não paramétrico denominado MannWhitney, usando o software gratuito BioEstat 5.0. Nesse mesmo sentido, para avaliar se as duplas apresentaram avanço em relação aos elementos que constituem o gênero, determinaram-se, com base em uma ficha de avaliação de narrativas digitais (Fand) adaptada de Cecchin (2015), 11 elementos que poderiam estar presentes nas produções. Para cada um deles, criou-se uma pontuação entre zero e quatro, podendo, então, uma ND obter um total de até 44 pontos. Na sequência, dividiu-se esse total em cinco níveis de proficiência: inexistente, caso a pontuação total da dupla fosse até 8,8 pontos; abaixo do básico, entre 8,9 e 17,6; básico, entre 17,7 e 24,6, mostrando que houve um domínio mínimo do gênero; adequado, entre 24,7 e 35,2; e plenamente satisfatório, entre 35,3 e 44 pontos. Logo após essa classificação, aplicou-se novamente o teste estatístico MannWhitney para verificar se houve diferença significativa entre a primeira e a última versão das ND.

Somente após as etapas de seleção, triangulação e análise dos dados coletados, foi possível apresentar os resultados da pesquisa, como descrito no próximo tópico.

\section{Resultados e discussões}

Para compreender o processo de apropriação de ND e as emoções implicadas, levou-se em conta a relação aluno-software, aluno-aluno, alunoprofessora e aluno-pesquisadora, isto é, a ação mediada (Wertsch, 1993, 1999) composta por seus cinco elementos.

Antes de apresentar e discutir os dados à luz das teorias que dialogam com este artigo, faz-se importante ressaltar que o objetivo não é o de comparar as informações advindas da realização do CP com as do EC, pois, em conformidade com Hornink e Compiani (2017), para que seja possível analisar essas informações, é fundamental a referência ao contexto de inserção de cada caso. Dessa forma, neste trabalho, apresentam-se apenas os dados advindos do EC. 
Por conseguinte, elaborada a partir dos dados do TEE, com base em estatística descritiva (Doria Filho, [s. d.]), a Tabela 1 apresenta os resultados das emoções positivas vivenciadas pelos sujeitos ao construírem suas ND no Scratch. De acordo com tais dados, houve o predomínio de emoções positivas durante o uso do software para produzir as ND, pois os alunos, em sua maioria, concordaram fortemente que se sentiram satisfeitos, felizes, empolgados, comprometidos e orgulhosos.

\section{Tabela 1 - Resultados de estatística descritiva do Teste dos Estados Emocionais - emoções positivas}

\begin{tabular}{|c|c|c|c|c|c|c|c|c|c|c|c|c|c|c|}
\hline \multirow[b]{2}{*}{ Emoção } & \multirow[b]{2}{*}{ Estatística } & \multicolumn{13}{|c|}{ Encontros } \\
\hline & & $\begin{array}{c}E \\
1\end{array}$ & $\begin{array}{l}\mathbf{E} \\
2\end{array}$ & $\begin{array}{l}E \\
3\end{array}$ & $\begin{array}{l}E \\
4\end{array}$ & $\begin{array}{l}\mathbf{E} \\
5\end{array}$ & $\begin{array}{l}E \\
6\end{array}$ & $\begin{array}{l}\mathrm{E} \\
7\end{array}$ & $\begin{array}{l}E \\
8\end{array}$ & $\begin{array}{l}\mathbf{E} \\
9\end{array}$ & $\begin{array}{c}E \\
10\end{array}$ & $\begin{array}{c}E \\
11\end{array}$ & $\begin{array}{c}E \\
12\end{array}$ & Geral \\
\hline Satisfeito & Mediana & 5 & 5 & 5 & 5 & 5 & 5 & 4,5 & 5 & 5 & 5 & 5 & 5 & 5 \\
\hline Feliz & Mediana & 5 & 5 & 5 & 5 & 5 & 5 & 5 & 5 & 5 & 5 & 5 & 5 & 5 \\
\hline Empolgado & Mediana & 5 & 5 & 5 & 5 & 5 & 5 & 3,5 & 5 & 5 & 5 & 5 & 5 & 5 \\
\hline Comprometido & Mediana & 5 & 5 & 5 & 5 & 5 & 5 & 4,5 & 5 & 5 & 5 & 5 & 5 & 5 \\
\hline Orgulhoso & Mediana & 4 & 5 & 5 & 5 & 5 & 5 & 4,5 & 5 & 5 & 5 & 5 & 5 & 5 \\
\hline
\end{tabular}

Fonte: Elaboração própria, com base em Brochado (2019).

Hargreaves (2003) afirma que as experiências de poder (sucesso ou fracasso) das pessoas permitem a formação das emoções vivenciadas. $\mathrm{O}$ autor ainda relata que, quando conseguem realizar com êxito aquilo a que se propuseram, é mais provável que as pessoas se sintam satisfeitas e orgulhosas. O relato do aluno A da dupla C, no segundo encontro, corrobora tais apontamentos quando afirma, na questão aberta do TEE, estar "orgulhoso por conseguir fazer uma animação". Na primeira cena da narrativa final dessa mesma dupla, há uma ave que se movimenta, como confirma a Figura 2. Tais dados permitem afirmar que o fato de o aluno ter se sentido orgulhoso por conseguir executar uma ação pode ter potencializado a qualidade da narrativa construída.

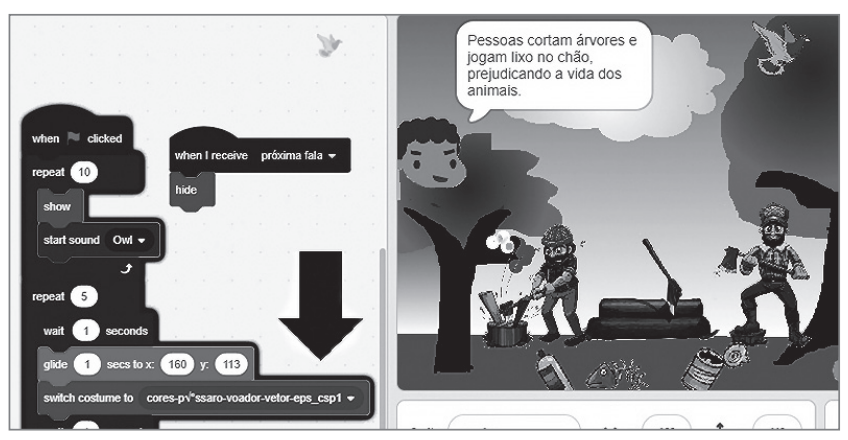

Figura 2 - Trecho da versão final da narrativa digital da dupla C

Fonte: Scratch (2018a). 
Importante citar que os adolescentes manifestaram suas emoções com bastante naturalidade. Por exemplo, a aluna A da dupla A diz se sentir feliz demais e que vai sair da sala de informática dando pulos. Pulos, gritos e palmas foram manifestações muito presentes durante os encontros, como visto na linha 13 do Episódio 1 (Quadro 1). Outro exemplo foi o caso do aluno B da dupla D que, ao comemorar uma ação do personagem que a dupla estava criando, quase caiu da cadeira, tamanha a empolgação.

\section{Quadro 1 - Episódio vivenciado durante o terceiro encontro}

\begin{tabular}{|c|c|}
\hline Elementos da pentádica & Enunciados e contextualização do episódio \\
\hline 1. Cena & Laboratório de informática da escola \\
\hline 2. Agentes & Professora, pesquisadora e alunos \\
\hline 3. Propósito & Reconhecimento das funcionalidades do Scratch \\
\hline 4. Ato & $\begin{array}{l}\text { Produção de projetos: uso de falas e movimento } \\
\text { no Scratch }\end{array}$ \\
\hline 5. Agência & Ferramenta Scratch, gestos e enunciados \\
\hline 6. Pesquisadora & $\begin{array}{l}\text { Nesse encontro, o objetivo era que as duplas } \\
\text { movimentassem seus personagens para que } \\
\text { passassem a dominar esse recurso. Enquanto } \\
\text { elaboravam seus projetos, a dupla G me chamou }\end{array}$ \\
\hline 7. Aluna A da dupla G & $\begin{array}{l}\text { Olha, dona (maneira como os alunos chamam os } \\
\text { professores), conseguimos animar um unicórnio }\end{array}$ \\
\hline 8. Pesquisadora & $\begin{array}{l}\text { Mas o unicórnio está nos personagens } \\
\text { (disponibilizados pelo) do Scratch? }\end{array}$ \\
\hline 9. Aluna B da dupla G & Não. Nós copiamos da internet. \\
\hline 10. Pesquisadora & Ah, é? E como vocês fizeram? \\
\hline 11. Aluna A da dupla G & $\begin{array}{l}\text { Nois pegô as imagens, editô e montô como } \\
\text { aprendemos (sic) }\end{array}$ \\
\hline 12. Pesquisadora & Elas colocam o projeto para rodar mais uma vez \\
\hline \multicolumn{2}{|c|}{ Episódio $1-3^{\circ}$ encontro do estudo de caso } \\
\hline Elementos da pentádica & Enunciados e contextualização do episódio \\
\hline 13. Aluna A da dupla G & $\begin{array}{l}\text { Olha, tá vuano (seria cavalgando) na praaaiiaaa... } \\
\text { Aaaaaaaadorei (sic) (falando bem alto, aplaudindo, } \\
\text { comemorando) }\end{array}$ \\
\hline 14. Pesquisadora & $\begin{array}{l}\text { A dupla continuou animando outros personagens. } \\
\text { No fim do encontro, as alunas da dupla chamam a } \\
\text { professora para ver o que tinham feito }\end{array}$ \\
\hline 15. Aluna A da dupla G & Conseguimos (dirigindo-se à professora) \\
\hline 16. Aluna B da dupla G & Tá loco, super legal (sic) \\
\hline
\end{tabular}

Fonte: Notas de pesquisa da primeira autora. 
Segundo Hargreaves (2003, p. 243, tradução nossa7 ), "[...] triunfo é uma das mais fortes fontes de emoção positiva entre as pessoas". Percebe-se nas linhas 15 e 16 do Quadro 1 que as alunas assumem conseguir executar com êxito as ações que lhes foram propostas, ou seja, fizeram com que os personagens do projeto elaborado se movimentassem. Ao concluir que conseguiram, a aluna B da dupla G afirma que aquela ação foi "super legal".

Ao analisar essa ação mediada, considera-se que o fato de a dupla ter atingido o objetivo proposto para o encontro permitiu que se observasse o predomínio de emoções positivas - como visto na Tabela 1. Percebe-se ainda a presença destas no enunciado proferido no TEE pela aluna B da dupla $\mathrm{H}$ no oitavo encontro, no qual comenta: "Estou muito feliz e orgulhosa por terminar".

Além da presença de emoções positivas em uma ação, há também as negativas. No entanto, antes de discutir tais questões, ressalta-se que os alunos tiveram 12 encontros para elaborar suas ND. Nos quatro primeiros encontros, apenas tiveram contato com as potencialidades do Scratch. No quinto, sem grandes interferências das pesquisadoras presentes, entregaram uma primeira versão dos textos. Depois disso, as intervenções aconteceram pontualmente, ou seja, cada dupla precisou de orientações específicas, as quais foram dadas também por alguns alunos que participaram do $\mathrm{CP}$, os quais foram convidados para serem monitores no EC a fim de auxiliarem nas atividades. É relevante destacar que algumas dessas duplas, como é o caso da $\mathrm{H}$, terminaram seus textos antes das demais e passaram a ajudar aquelas que tinham mais dificuldade, com os alunos monitores.

Para Wertsch, Del Río e Alvarez (1998), ao se inserir uma nova ferramenta, pode-se perceber modificações em um dado contexto. Com base nessa afirmação, buscou-se apoio para analisar os resultados com relação à ansiedade, emoção tida como negativa, manifestada pelos sujeitos. Quando se deu início ao segundo momento da SD na sala de informática da escola, uma nova ferramenta cultural, isto é, a linguagem de programação Scratch, foi apresentada a eles. Nesse primeiro encontro, os alunos concordam que se sentiram ansiosos, como apresentado na Tabela 2. Este estudo se ancorou no pressuposto postulado por Wertsch, Del Río e Alvarez (1998) para conjecturar que a ansiedade se fez presente pela introdução de uma nova ferramenta nesse contexto. A partir desses dados, depreende-se que, conforme os alunos dominavam as ferramentas, a presença da ansiedade foi menos marcante nos encontros.

\section{Tabela 2 - Resultados de estatística descritiva do Teste dos Estados Emocionais - emoções negativas}

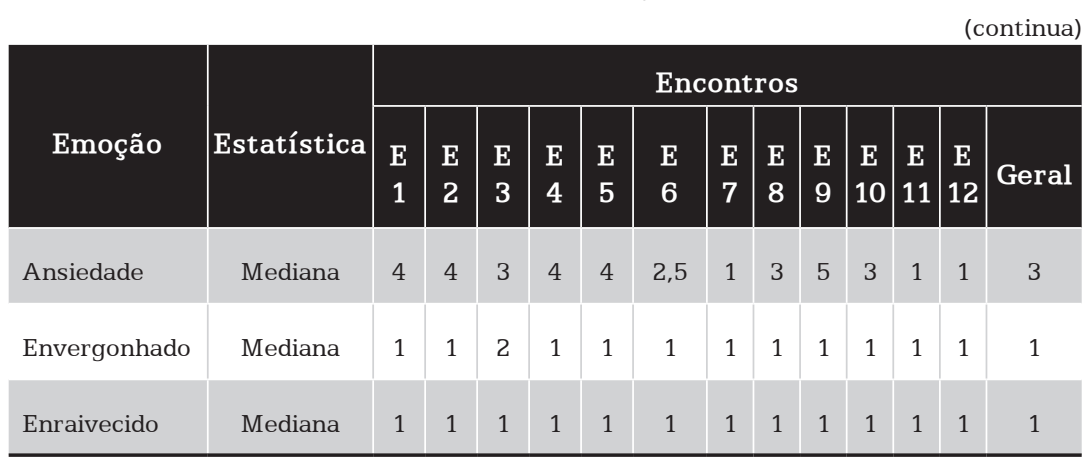

\footnotetext{
"[...] el triunfo es una de las fuentes de emoción positiva más fuertes entre la gente".
} 


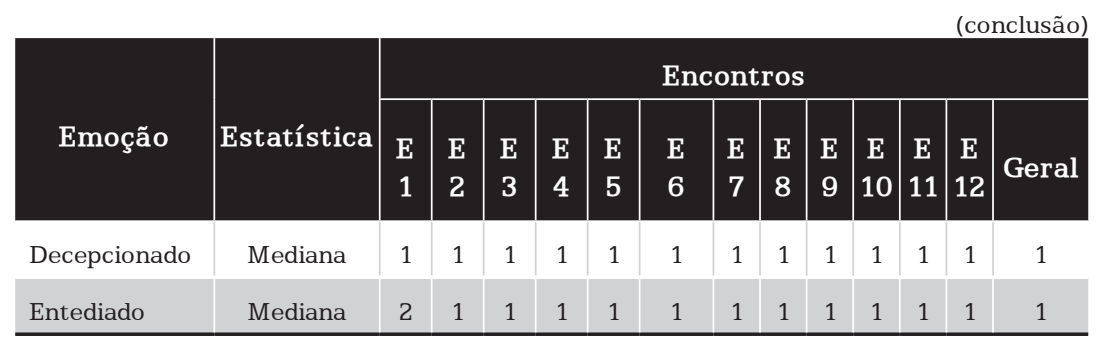

Fonte: Elaboração própria, com base em Brochado (2019).

Hargreaves (2003) destaca que, quando as pessoas encontram dificuldades para realizar seus propósitos, costumam sentir ansiedade, frustração e outras emoções negativas. No entanto, de acordo com RebolloCatalán et al. (2014, p. 72, tradução nossa ${ }^{8}$ ), alguns estudos sustentam que a presença da ansiedade em pequenas proporções, como a verificada nesta pesquisa, é importante para "[...] despertar o desejo de aprender, gerar curiosidade e manter a atenção [dos alunos] focada". Rebollo-Catalán et al. (2014, p. 72, tradução nossa ${ }^{9}$ ) destacam ainda que a presença da ansiedade em situações que envolvem ensino e aprendizagem pode

[...] estar associada a fatores como a suposição de um novo papel do aprendiz, o desafio que um novo conhecimento pode supor na estrutura de conhecimento anterior do aluno, a incerteza sobre suas próprias habilidades para executar tarefas e a memória de experiências negativas anteriores de aprendizagem.

Nesse contexto, compreende-se o porquê de, no encontro de número nove, os alunos concordarem fortemente que se sentiram ansiosos. O fato de algumas duplas estarem com suas ND próximas do fim enquanto outras refaziam seus textos pode ter favorecido esse resultado. A medida que algumas duplas terminavam suas produções, auxiliavam as demais, com os monitores. Esse auxílio e a certeza de que todos teriam suas produções concluídas podem ter levado os alunos a não concordarem nem discordarem de que estavam ansiosos no encontro de número dez e a discordarem totalmente nos dois últimos encontros.

Compiani (2013 apud Diniz; Compiani, 2017) alerta que o contexto deve ser tanto o ponto de partida quanto o de chegada ao se elaborar conhecimento no ambiente escolar. Considerando esse alerta, outro aspecto bastante importante a ser destacado e que esteve presente em todas as ND foi o fato de os alunos retratarem o meio no qual estão acostumados

" "...] despertar el deseo de aprender, generar curiosidad y mantener la atención focalizada".

9 "[...] estar asociada a factores como la asunción de un nuevo rol del aprendiz, el desafío que un conocimiento nuevo puede suponer en la estructura de conocimiento previo del estudiante, la incertidumbre sobre las propias capacidades para realizar las tareas y el recuerdo de experiencias negativas previas de aprendizaje". a viver e, com base no problema escolhido para discussão, apresentaram uma proposta de solução. A Figura 3 demonstra a lateral da escola onde a pesquisa aconteceu. Os alunos, antes de iniciarem suas produções, fizeram um estudo de campo, ainda quando estavam lendo textos para alimentação temática das ND, e constataram que havia lixo jogado na calçada da escola. Dessa forma, quando a dupla A elaborou seu texto, introduziu uma placa com os dizeres "mantenha a cidade limpa". Disso, depreende-se que os alunos refletiram a partir das questões do meio em que estão inseridos e resolveram qual seria a solução para o problema. Tal possibilidade se configura como uma opção que favorece o aluno a se sentir orgulhoso, pois, mediante o exercício, pode valorizar sua casa, sua escola, sua comunidade, sua vida. 


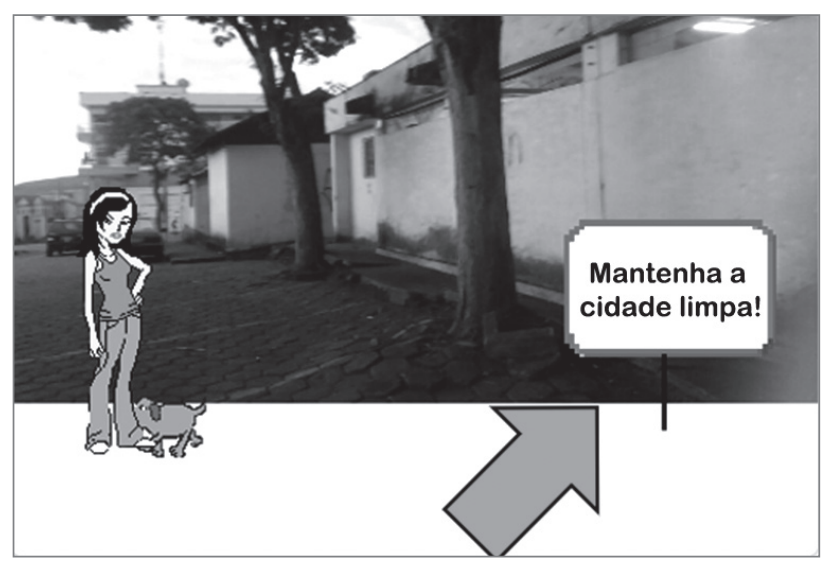

Figura 3 - Trecho da versão final da narrativa digital da dupla A

Fonte: Scratch (2018b).

No nono encontro, a aluna B da dupla A afirma no TEE: "Estou muito orgulhosa porque eu e minha parceira conseguimos [terminar a ND], falta só mais algumas coisinhas básicas e está ficando muito bom". A manifestação da aluna comprova o quanto está satisfeita com sua produção. Tal fato se deu pois, conforme defendem Diniz e Compiani (2017), as atividades desenvolvidas não se resumiram a reprodução fragmentada, isto é, consideraram também a realidade dos alunos envolvidos.

Analisaram-se, além das ND em si, as habilidades ${ }^{10}$ do pensamento computacional envolvidas. A Tabela 3, com os dados advindos do software Dr. Scratch, mostra que houve avanço significativo ao comparar a primeira versão (recolhida no quinto encontro) à última. Com tais dados, realizou-se o teste estatístico não paramétrico Mann-Whitney, com o objetivo de verificar se havia diferença significativa entre a primeira e a última versão dos textos. Com nível de significância de 0,05, rejeitou-se a hipótese nula de que não havia diferença significativa entre as versões, pois o valor de $\mathrm{p}(\mathrm{p}=0,00)$ resultou menor que o índice proposto.

\section{Tabela 3 - Dados do Dr. Scratch ao avaliar as habilidades do pensamento computacional utilizado nas narrativas digitais}

\begin{tabular}{|c|c|c|c|c|c|c|c|c|c|c|c|c|c|c|c|c|c|}
\hline \multicolumn{2}{|c|}{ Duplas } & \multicolumn{2}{|c|}{ A } & \multicolumn{2}{|c|}{ B } & \multicolumn{2}{|c|}{ C } & \multicolumn{2}{|c|}{ D } & \multicolumn{2}{|c|}{$\mathbf{E}$} & \multicolumn{2}{|c|}{ F } & \multicolumn{2}{|c|}{ G } & \multicolumn{2}{|c|}{$\mathbf{H}$} \\
\hline \multicolumn{2}{|c|}{$\begin{array}{l}\text { Versão inicial } \\
\text { (VI) e Versão } \\
\text { final (VF) }\end{array}$} & VI & VF & VI & VF & VI & VF & VI & VF & VI & VF & VI & VF & VI & VF & VI & VF \\
\hline $\begin{array}{l}\mathrm{P} \\
\mathrm{O}\end{array}$ & $\mathrm{L}^{* *}$ & 0 & 3 & 0 & 3 & 0 & 1 & 0 & 3 & 0 & 2 & 0 & 0 & 2 & 3 & 2 & 3 \\
\hline $\begin{array}{l}\mathrm{N} \\
\mathrm{T} \\
\mathrm{U}\end{array}$ & $\mathrm{P}^{* *}$ & 1 & 3 & 1 & 3 & 1 & 3 & 1 & 3 & 1 & 3 & 1 & 3 & 1 & 3 & 0 & 3 \\
\hline $\begin{array}{l}\text { A } \\
\text { C }\end{array}$ & $I^{* *}$ & 2 & 2 & 2 & 2 & 1 & 2 & 2 & 2 & 1 & 2 & 1 & 1 & 2 & 2 & 2 & 2 \\
\hline 0 & $\mathrm{R}^{* *}$ & 1 & 1 & 1 & 2 & 1 & 1 & 1 & 1 & 1 & 1 & 1 & 1 & 1 & 1 & 1 & 2 \\
\hline
\end{tabular}

${ }_{10}$ As habilidades avaliadas foram: lógica, paralelismo, interatividade com o usuário, representação de dados, controle de fluxo, sincronização e abstração. 


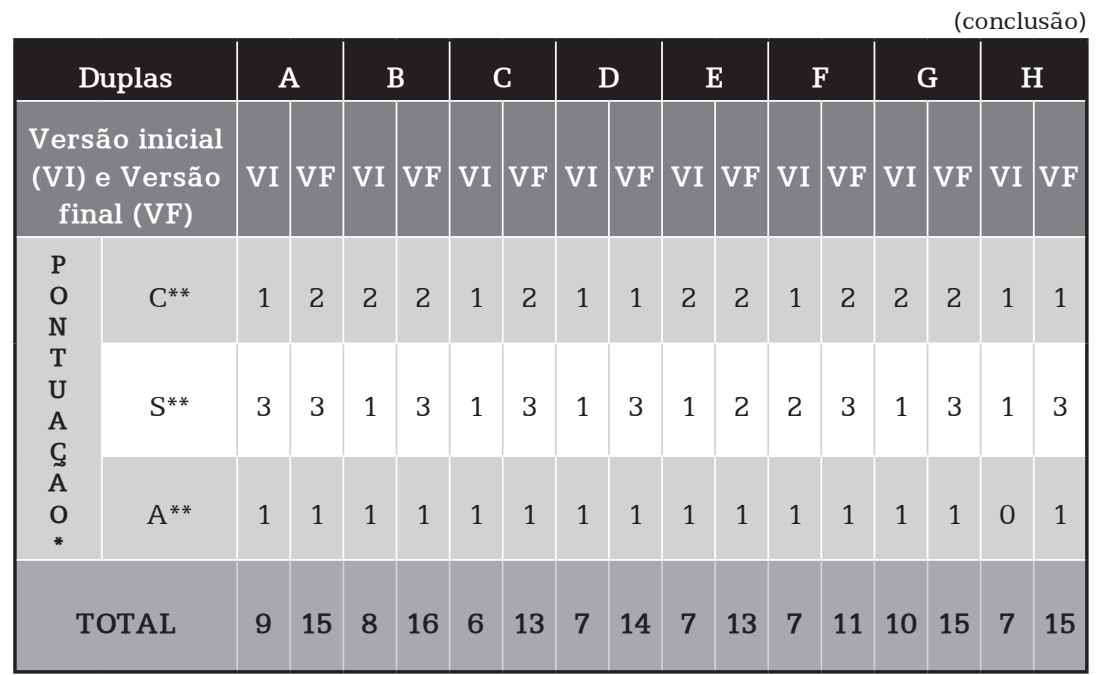

Fonte: Brochado (2019, p. 159).

*Pontuação do Dr. Scratch para as categorias da dimensão dos conceitos computacionais.

** L = lógica; $\mathrm{P}$ = paralelismo; I = interatividade com usuário; $\mathrm{R}$ = representação de dados; $\mathrm{C}=$ controle de fluxo; $\mathrm{S}=$ sincronização; $\mathrm{A}=$ abstração.

Um exemplo que comprova o avanço da dupla E é apresentado nas Figuras 4 e 5. Na primeira versão do texto (Figura 4), a dupla deixou a fala da personagem feminina aparente durante todo o tempo de exibição do projeto. Isso fez com que, quando proferida, a fala do personagem masculino se sobrepusesse à da personagem feminina, o que dificultava a leitura da história. Além disso, esteticamente, também prejudicava a ND.

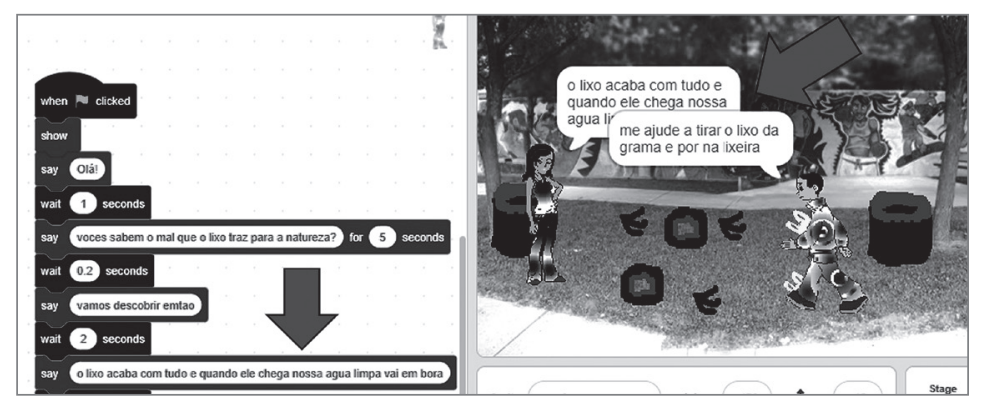

Figura 4 - Trecho da versão inicial da narrativa digital da dupla E

Fonte: Scratch (2018c).

Por sua vez, a Figura 5 testemunha o progresso apresentado pela dupla, que percebeu a necessidade de determinar um tempo de exibição para a fala de cada personagem. Cinco segundos foram suficientes para que o público conseguisse ler a fala dos personagens, entendesse a história e seguisse os acontecimentos das cenas com facilidade. 


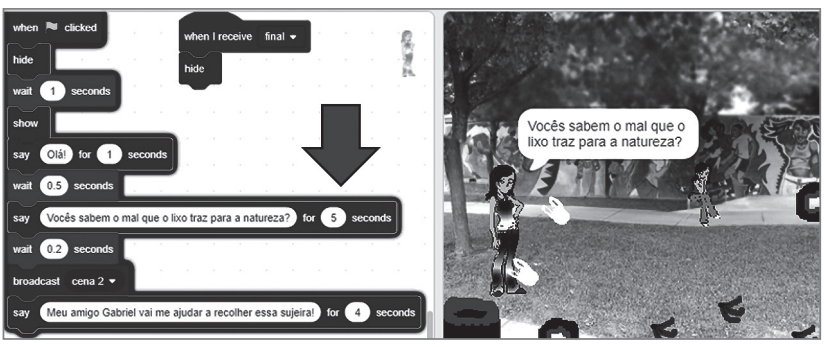

Figura 5 - Trecho da versão final da narrativa digital da dupla E

Fonte: Scratch (2018d).

Outra evolução percebida foi o fato de a dupla adicionar comandos mais complexos, por exemplo, para a personagem desaparecer quando recebesse a palavra "final" (Figura 5). Essas melhoras comprovam o aprimoramento tanto da qualidade das narrativas em si quanto das habilidades do PC.

Para avaliar o aspecto qualitativo das ND, adaptou-se uma ficha (Quadro 2) de Cecchin (2015), cujo objetivo era analisar em que proporção os elementos que compõem o gênero estavam ou não presentes nos textos.

Quadro 2 - Ficha para avaliação das narrativas digitais

\begin{tabular}{|c|c|c|c|c|c|c|}
\hline \multirow{2}{*}{ Dimensões } & \multirow{2}{*}{$\begin{array}{l}\text { Critérios de avaliação das } \\
\text { narrativas digitais }\end{array}$} & \multicolumn{5}{|c|}{ Pontuação } \\
\hline & & 0 & 1 & 2 & 3 & 4 \\
\hline \multirow{5}{*}{$\begin{array}{l}\text { 1. Geral: } \\
\text { estrutura do } \\
\text { gênero }\end{array}$} & $\begin{array}{l}1.1 \text { O texto apresenta uma } \\
\text { questão dramática com início, } \\
\text { desenvolvimento, conflito e } \\
\text { resolução ao final }\end{array}$ & & & & & \\
\hline & $\begin{array}{l}\text { 1.2 As marcas linguísticas (ou } \\
\text { imagéticas) permitem reconhecer } \\
\text { os participantes }\end{array}$ & & & & & \\
\hline & $\begin{array}{l}1.3 \text { O enredo apresenta marcas } \\
\text { linguísticas que determinam as } \\
\text { circunstâncias da narrativa (tempo, } \\
\text { espaço, causa) }\end{array}$ & & & & & \\
\hline & $\begin{array}{l}\text { 1.4 Há ordenação de fatos e } \\
\text { acontecimentos }\end{array}$ & & & & & \\
\hline & $\begin{array}{l}1.5 \text { O público tem tempo suficiente } \\
\text { para ler/ouvir, entender o texto }\end{array}$ & & & & & \\
\hline
\end{tabular}




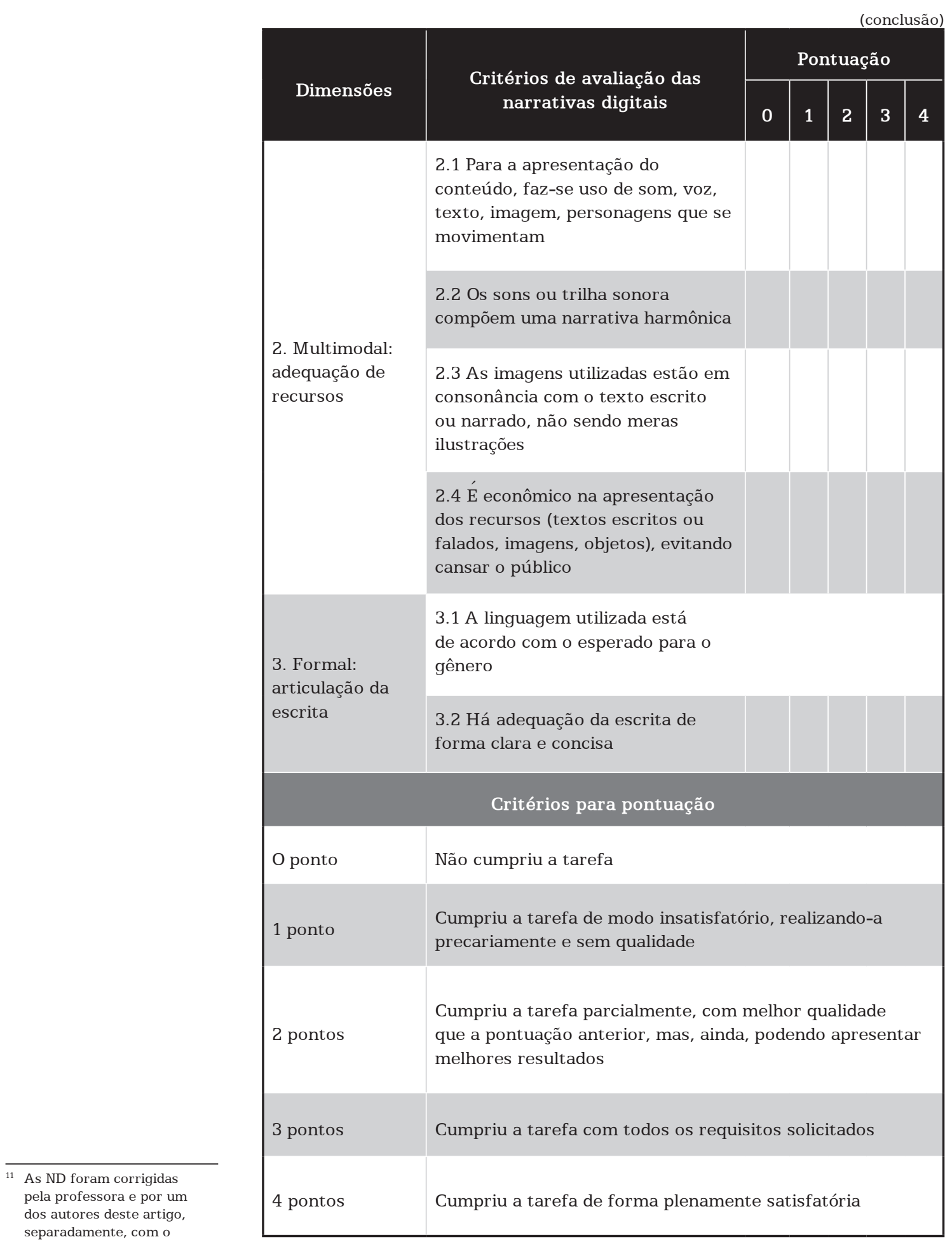

separadamente, com o

objetivo de verificar se

a ficha utilizada como

parâmetro tinha critérios

coesos. Dessa forma,

estabeleceu-se a média com

esses resultados para, a

partir dela, criar a Tabela 4.
Fonte: Brochado (2019, p. 87-88)

A Tabela 4 apresenta o resultado da média ${ }^{11}$ da correção das primeiras e das últimas versões das ND. Realizou-se o teste de Mann-Whitney com o propósito de verificar se havia ou não diferença significativa entre 
as versões. Com valor de $\mathrm{p}(\mathrm{p}=0,00)$ abaixo do índice 0,05 estipulado, rejeitou-se a hipótese nula de que não havia diferença significativa entre as versões.

Tabela 4 - Média entre pontuação da correção da professora e da pesquisadora e diferença entre pontuação inicial e final das narrativas digitais

\begin{tabular}{|l|c|c|c|}
\hline \multicolumn{1}{|c|}{ Dupla } & $\begin{array}{c}\text { Correção } \\
\text { da versão inicial }\end{array}$ & $\begin{array}{c}\text { Correção } \\
\text { da versão final }\end{array}$ & Diferença \\
\hline Dupla A & 18 & 37 & 19 \\
\hline Dupla B & 18,5 & 38 & 19,5 \\
\hline Dupla C & 13 & 36 & 23 \\
\hline Dupla D & 17,5 & 39 & 21,5 \\
\hline Dupla E & 18 & 38 & 20 \\
\hline Dupla F & 19 & 38 & 19 \\
\hline Dupla G & 23 & 39 & 23 \\
\hline Dupla H & 18 & 41 & 20,1 \\
\hline Média geral & 18,1 & 38,3 & \\
\hline
\end{tabular}

Fonte: Brochado (2019, p. 166).

As Ilustrações 6 e 7 comprovam a evolução da dupla $\mathrm{F}$ em relação à coerência da ND. A história da dupla era a de que a sociedade não cuidou de todo o lixo produzido e esse montante se transformou em um monstro. Para combatê-lo, essa mesma sociedade precisou criar uma inteligência artificial. No entanto, ao assistir à primeira versão, não era possível entender essa narrativa. Depois das intervenções, a dupla resolveu a questão contextualizando a história com uma imagem inicial.

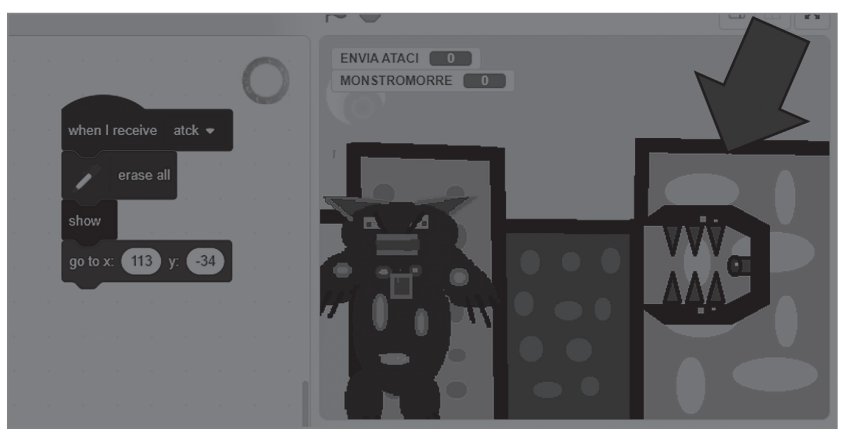

Figura 6 - Trecho da versão inicial da narrativa digital da dupla $\mathrm{F}$

Fonte: Scratch (2018e). 


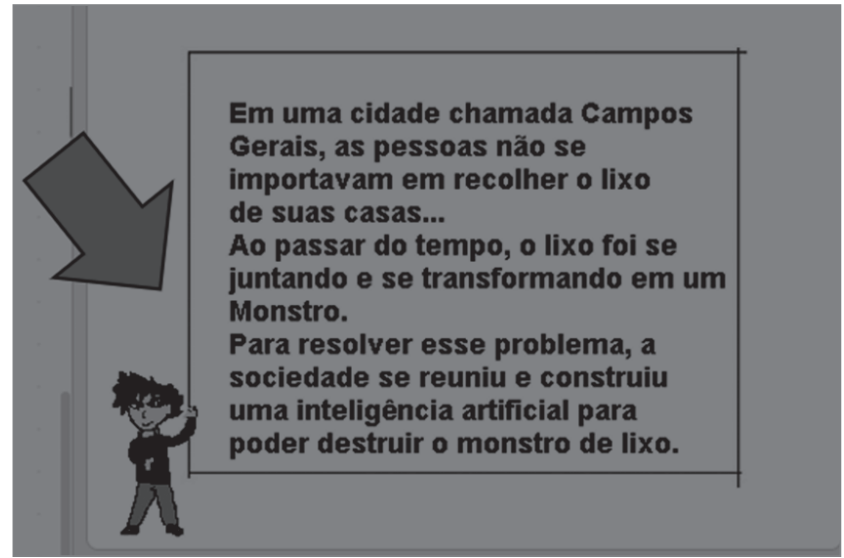

Figura 7 - Trecho da versão final da narrativa digital da dupla F

Fonte: Scratch (2018f).

Por fim, ressalta-se que havia uma questão aberta no TEE para que os alunos pudessem mencionar alguma emoção não presente no teste, mas que tivessem vivenciado durante o uso do Scratch. Vários deles comentaram estar enraivecidos, pois as atividades desenvolvidas se aproximavam do fim. Dentre esses, a aluna A da dupla E, no penúltimo encontro, surpreendeu ao criar, com as emoções distribuídas em escala, uma nova categoria de emoção (Figura 8), dizendo estar fortemente triste.

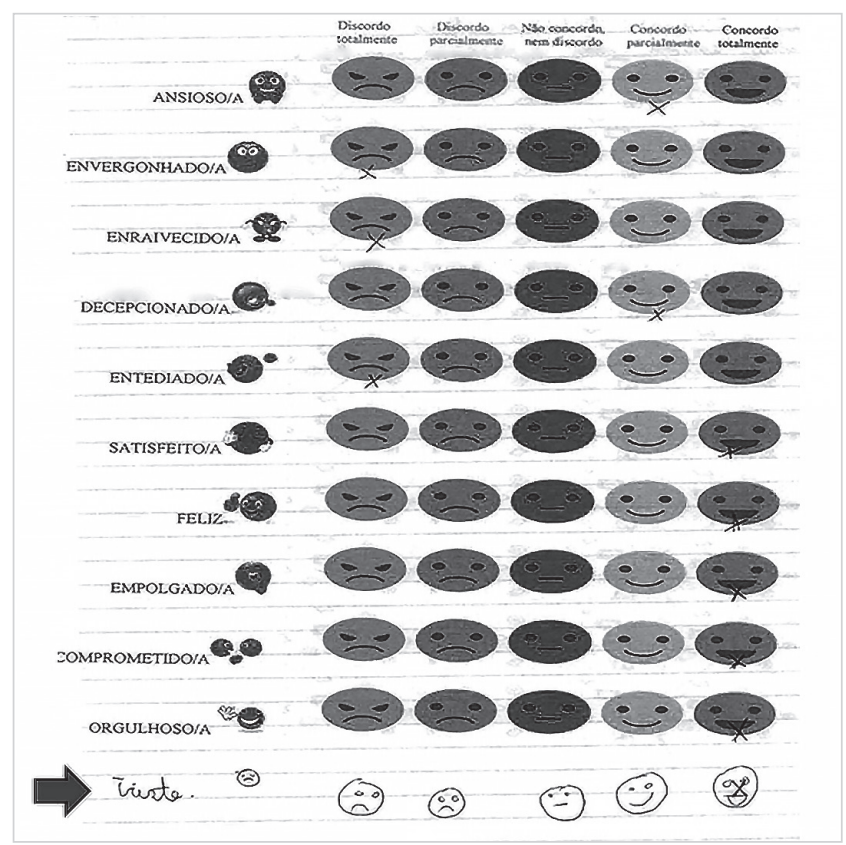

Figura 8 - Criação de uma nova categoria de emoção pela aluna A da dupla E

Fonte: Brochado (2019, p. 141). 
A aluna explica estar triste com o fim das atividades desenvolvidas na sala de informática. Com isso, conclui-se que, por trabalhar com atividades contextualizadas e lúdicas, os envolvidos tiveram muito prazer em realizar tais ações, além de serem construtores de seu próprio conhecimento.

\section{Considerações finais}

Com base em Wertsch (1993, 1999) e Rebollo-Catalán et al. (2014), foi possível identificar e compreender as emoções presentes durante o uso do software Scratch na construção de narrativas digitais. Os dados produzidos demonstram que o uso de tal ferramenta cultural propiciou aos sujeitos vivenciar emoções positivas, como felicidade, orgulho e empolgação. Além dessas, a ansiedade, tida como uma emoção negativa, também se fez presente. No entanto, em conformidade com Rebollo-Catalán et al. (2014), considerou-se que a ansiedade, em pequenas proporções, como foi o caso, favoreceu o desenvolvimento das atividades.

Com isso, conclui-se que o Scratch é uma ferramenta cultural que pode despertar nos estudantes o desejo de aprender de maneira lúdica, afinal, o software favorece que o aluno assuma o papel de autor de sua própria narrativa, desafiando-o a construir, em interação com os outros indivíduos, seu conhecimento, proporcionando experiências positivas para a relação ensino e aprendizagem.

\section{Referências}

ANDRÉ, M. E. D. A. Estudo de caso em pesquisa e avaliação educacional. Brasília: Liber Livro, 2005.

BAKHTIN, M. Estética da criação verbal. Tradução de Maria Ermantina Galvão G. Pereira. 2. ed. São Paulo: Martins Fontes, 1997.

BARBOSA, J. G.; HESS, R. O diário de pesquisa: o estudante universitário e seu processo formativo. Brasília: Liber Livro, 2010.

BARDIN, L. Análise de conteúdo. Tradução de Luís Antero Reto e Augusto Pinheiro. São Paulo: Edições 70, 2016.

BROCHADO, E. A. Scratch como fator mobilizador para produção de narrativas digitais. 2019. 197 f. Dissertação (Mestrado em Educação) Universidade Federal de Alfenas, Alfenas, 2019.

BROCHADO, E. A.; SILVA, M. A.; HORNINK, G. G. Scratch: considerações à luz da ação mediada. In: CONGRESSO INTERNACIONAL 
DE EDUCAÇÃO E TECNOLOGIAS; ENCONTRO DE PESQUISADORES EM EDUCAÇÃO À DISTÂNCIA, 4., 2018, São Carlos. Anais... São Carlos, SP: Grupo Horizonte/SEaD/UFSCar, 2018. p. 1-13.

CECCHIN, A. S. Práticas de multiletramentos no contexto escolar: investigação de uma abordagem para o ensino de produção de narrativas digitais. 2015. 168 f. Dissertação (Mestrado em Tecnologias Educacionais em Rede) - Centro de Educação, Universidade Federal de Santa Maria, Santa Maria, RS, 2015.

DAMÁSIO, A. R. O erro de Descartes: emoção, razão e o cérebro humano. Tradução de Dora Vicente e Georgina Segurado. São Paulo: Companhia das Letras, 1996.

DINIZ, V. L.; COMPIANI, M. O ensino de Geografia e suas relações com a pedagogia crítica do lugar: contribuições para uma prática interdisciplinar. Geografia, Ensino \& Pesquisa, Santa Maria, RS, v. 21, n. 1, p. 65-77, jan./abr. 2017.

DORIA FILHO, U. Introdução à Bioestatística para simples mortais. São Paulo: Negócio Editora, [s. d.].

DR. SCRATCH: analyze your Scratch projects here! 2019. Available in: $<$ http://www.drscratch.org/>.

Access in: 19 Nov. 2020.

FARIAS, H.; BONIFÁCIO, B.; FERREIRA, R. Avaliando o uso da ferramenta Scratch para ensino de programação através de análise quantitativa e qualitativa. In: SIMPÓSIO BRASILEIRO DE INFORMÁTICA NA EDUCAÇÃO, 26., 2015, Maceió. Anais... Maceió: Sociedade Brasileira de Computação, 2015. p. 947-956.

HARGREAVES, A. La política emocional en el fracaso y en el éxito escolar. In: ULLASTRES, A. A.; GIL, C. C. El fracaso escolar: una perspectiva internacional. Alianza Editorial, 2003. p. 229-254.

HORNINK, G. G. Cartografando online: caminhos da informática na escola com professores que elaboram conhecimentos em formação contínua. 2010. 296 f. Tese (Doutorado em Ciências) - Instituto de Geociências, Universidade Estadual de Campinas, Campinas, 2010.

HORNINK, G. G.; COMPIANI, M. Reflections of online mediations in the process of continuing teacher training focusing on local environmental problems. Educação Temática Digital, Campinas, v. 19, n. 4, p. 773-794, out./dez. 2017.

LIKERT, R. A technique for the measure of attitudes. Belmount: Wadsworth Publishing Company, 1932. 
LONGHI, M. T. et al. Um estudo sobre os fenômenos afetivos e cognitivos em interfaces para softwares educativos. Revista Renote: Novas Tecnologias em Educação, Porto Alegre, v. 5, n. 1, p. 1-10, jul. 2007.

MEIRINHOS, M.; OSÓRIO, A. O estudo de caso como estratégia de investigação em educação. Eduser: Revista de Educação, Bragança, Portugal, v. 2, n. 2, p. 49-65, dez. 2010.

MINAYO, M. C. S. Pesquisa social: teoria, método e criatividade. Petrópolis: Vozes, 2002.

MORSE, J. M. Approaches to qualitative-quantitative methodological triangulation. Nursing Research, Philadelphia, v. 40, n. 2, p. 120-123, Mar./Apr. 1991.

MORTIMER, E. F. et al. Interações entre modos semióticos e a construção de significados em aulas de ensino superior. Ensaio: Pesquisa em Educação em Ciências, Belo Horizonte, v. 16, n. 3, p. 121-145, set./ dez. 2014.

REBOLLO-CATALÁN, M. A. et al. Las emociones en el aprendizaje online. Relieve, Valencia, v. 14, n. 1, p. 1-23, 2008.

REBOLLO-CATALÁN, M. A. et al. Las emociones en el aprendizaje universitario apoyado en entornos virtuales: diferencias según actividad de aprendizaje y motivación del alumnado. Revista Complutense de Educación, Madri, v. 25, n. 1, p. 69-93, 2014.

REBOLLO-CATALÁN, M. A.; HORNILLO-GÓMEZ, I. Perspectiva emocional en la construcción de la identidad en contextos educativos: discursos y conflictos emocionales. Revista de Educación, Madrid, v. 353, p. 235-263, sept./dic. 2010.

REBOLLO-CATALÁN, M. A.; HORNILLO-GÓMEZ, I.; GARCÍA-PÉREZ, R. El estudio educativo de las emociones: una aproximación sociocultural. Teoría de la Educación: Educación y Cultura en la Sociedad de la Información, Salamanca, v. 7, n. 2, p. 28-44, dic. 2006.

REIS, R. C. D. et al. Estado da arte sobre afetividade na formação de grupos em ambientes colaborativos de aprendizagem. Revista Brasileira de Informática na Educação, Porto Alegre, v. 23, n. 3, p. 113-130, dez. 2015 .

ROBIN, B. R. The power of digital storytelling to support teaching and learning. Digital Education Review, Barcelona, n. 30, p. 17-29, dic. 2016.

RODRIGUES, A. Mídias, efeitos de sentido e práticas de leitura e escrita: 
o que nos contam as narrativas digitais?. Leitura: Teoria \& Prática, Campinas, v. 37, n. 75, p. 101-113, 2019.

RODRIGUES, T. C.; TELES, L. F. O uso de mensagens eletrônicas instantâneas como recurso didático. Revista Brasileira de Estudos Pedagógicos, Brasília, v. 100, n. 254, p. 17-38, jan./abr. 2019.

SCRATCH. Versão final Dupla C GE. 2018a. Disponível em: <https:// scratch.mit.edu/projects/222117564/>. Acesso em: 23 nov. 2020.

SCRATCH. Versão final Dupla A GE. 2018b. Disponível em: <https:// scratch.mit.edu/projects/222116628/>. Acesso em: 23 nov. 2020.

SCRATCH. Versão 1 Dupla E GP. 2018c. Disponível em: <https:// scratch.mit.edu/projects/225665404/>. Acesso em: 23 nov. 2020.

SCRATCH. Versão final Dupla E GE. 2018d. Disponível em: <https:// scratch.mit.edu/projects/222119440/>. Acesso em: 23 nov. 2020.

SCRATCH. Versão 1 Dupla F GE. 2018e. Disponível em: <https:// scratch.mit.edu/projects/220790077/>. Acesso em: 23 nov. 2020.

SCRATCH. Versão final Dupla F GE. 2018f. Disponível em: <https:// scratch.mit.edu/projects/222119700/>. Acesso em: 23 nov. 2020.

SILVA, M. A. Criatividade literária na autoria de narrativas digitais multidisciplinares no Scratch. 2019. 172 f. Dissertação (Mestrado em Educação) - Universidade Federal de Alfenas, Alfenas, 2019.

TORMAN, V. B.; COSTER, R.; RIBOLDI, J. Normalidade de variáveis: métodos de verificação e comparação de alguns testes não-paramétricos por simulação. Revista HCPA, Porto Alegre, v. 32, n. 2, p. 227-234, 2012.

VIGOTSKY, L. S. Teoría de las emociones: estudio histórico-psicológico. Tradução de Judith Viaplana. Madrid: Ediciones Akal, 2004.

WERTSCH, J. V. Vygotsky y la formación social de la mente. Ciudad de México: Paidós, 1988.

WERTSCH, J. V. Voces de la mente: un enfoque sociocultural para el estudio de la acción mediada. Madrid: Visor, 1993.

WERTSCH, J. V. La mente en acción. Buenos Aires: Aique, 1999.

WERTSCH, J. V.; DEL RÍO, P.; ALVAREZ, A. Estudos socioculturais da mente. Tradução de Maria da Graça Paiva e André Rossano Teixeira Camargo. Porto Alegre: ArtMed, 1998. 
YIN, R. K. Estudo de caso: planejamento e métodos. 2. ed. Tradução de Daniel Grassi. Porto Alegre: Bookman, 2001.

YUKSELTURK, E.; ALTIOK, S. An investigation of the effects of programming with Scratch on the preservice IT teachers' self-efficacy perceptions and attitudes towards computer programming. British Journal of Educational Technology, Oxford, v. 48, n. 3, p. 789-801, May 2017.

Recebido em 26 de setembro de 2019. Aceito em 11 de agosto de 2020. 